\title{
A case study on the hydraulic environment of spawning ground based on the index of diversity
}

\author{
Ting-yu Li ${ }^{1, \text { a }}$, Yu-rong Wang ${ }^{1, b^{*}}$, Wei Huang ${ }^{2}$ \\ 1 State Key Lab. of Hydraulics and Mountain River Eng., Sichuan Univ., Chengdu 610065, China \\ 2China Institute of Water Resources and hydropower Research, Beijing, 100038, China \\ a1147605628@qq.com, b826733149@qq.com
}

Keywords: Ya-fish; Spawning ground; Shannon diversity; Hydraulic environment.

Abstract. In this study, we investigated the hydraulic environment heterogeneity of the Lijiahe spawning ground which locates in the downstream of Jinchuan River, one tributary of Dadu River. River2D was conducted to simulate the hydraulic environment, namely flow velocity and water depth, under different discharges. Shannon diversity index was used as mathematic principle in evaluating the heterogeneous level. According to the results, the optimum depth-velocity heterogeneity occurs when the discharge is $156 \mathrm{~m}^{3} / \mathrm{s}$.

\section{Introduction}

To determine the ecological flow rationally and accurately, various methods have been proposed ${ }^{[1,2]}$. Among these methods, Weighted Usable Area (WUA) is the most frequently used indicator and is generally believed that the bigger the WUA is, the better comfort of habitat the fish could have ${ }^{[3]}$. Generally, because spawning grounds demand less water depth and flow velocity than other habitats $\mathrm{do}^{[4]}$, the optimal WUA could be obtained when the ecological flow is relatively small. However, attention has been seldom focused on the change in complexity and discrepancy of hydraulic environment, such as water depth and flow velocity, in spawning ground after anthropogenic regulations.

River habitat provides aquatic organism all the space and environmental elements they need. Among all the environmental elements, hydraulic environment is the one of the most important parts ${ }^{[5]}$. Previous studies have pointed out that diversified habitat is beneficial to the growth of aquatic organism. For instance, Harman studied the relationship between fresh-water mollusca and the diversity of water substrate; concluded that with the type of water substrate increase, the diversity of fresh-water mollusk enhanced ${ }^{[6]}$. Miller et al. utilized meta-analysis to quantify macroinvertebrate's responses to the instream habitat restoration and proved that habitat heterogeneity will increase biodiversity ${ }^{[7]}$.

Inspired by above analyses, we put forward that hydraulic heterogeneity is a potential indicator in evaluating the suitability of spawning grounds. We chose water depth and flow velocity to present the hydraulic environment heterogeneity of spawning ground, divided them into different patches, hypothesized that diversified hydraulic environment could be an effective index in evaluating the condition of spawning ground after flow regulation.

\section{Methods}

Study site. Dams were built for hydropower on the Dadu River in China (Fig.1). However, these dams have drained away water previous flowed towards the downstream of river, which inevitably brought about negative impact on the spawning grounds of Ya-fish and caused it to be endangered. Lijiahe spawning ground, which locates in the water reduced channel, is one of the spawning grounds significantly affected by the construction. In order to mollify this condition, minimum ecological discharge is required. 


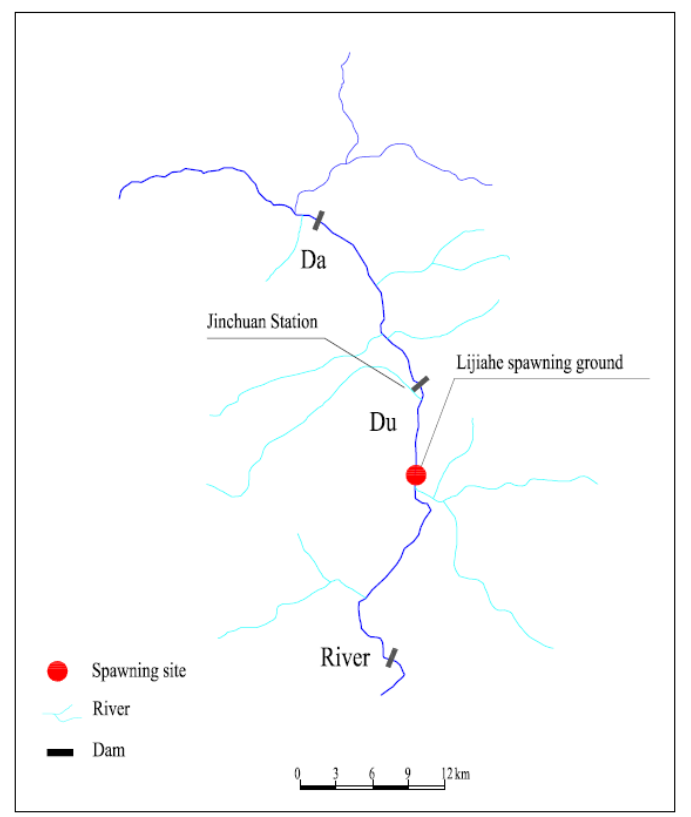

Fig. 1 Sketch map of Lijiahe spawning ground

Field data. Along with the bank of Ljiahe spawning ground, measuring section were arranged every $30 \mathrm{~m}$. On each measuring section, measuring points were plot every $10 \mathrm{~m}$. Coordinate points and underwater topography were measured. Statistics of fish were collected from Influence of Dadu River Jinchuan Hydropower Station on the Aquatic Organism and Diversity of Fish.

Modeling. Water depth offers comfortable hatching environment and space for their daily activities while flow velocity can change the migration routine, stimulate spawning and spread eggs. Sempeski et al. investigated grayling spawning sites in two French rivers, the Pollon and the Suran, found that the flow velocity of the two study sites were similar, and concluded that most of biotic behaviors of fish closely related with flow velocity ${ }^{[8]}$. Mior monitored hydraulic characteristics of spawning habitat utilized by Atlantic salmon in the Girnock Burn, and deemed water depth and flow velocity as rudimentary variance in depicting the hydraulic environment of spawning grounds ${ }^{[9]}$. Moreover, Ya-fish prefers to spawn in riffles-rapid area since rapid flow can stimulate Ya-fish to spawn while suitable water depth can provide proper space to the demersal egg ${ }^{[10,11]}$. Therefore, water depth and velocity were adopted as two major factors in evaluating the heterogeneous degree of hydraulic environment. However, because water depth distributes zonally and declines from centre towards two banks, which is different from the original distribution of landscape patch, we thereby considered water depth within defined scope as a whole rather than the discrepancy of each water depth. Water depth and flow velocity are classified according to the characteristic of mountain river and previous studies ${ }^{[12]}$ and shown in the following table 1 and table 2.

Table 1 Water depth patch classification

\begin{tabular}{ccccc}
\hline Type & Riffle & Mediate riffle & Mediate pool & PUnit: $\mathrm{m}$ ] \\
\hline Water depth & $0 \sim 0.5$ & $0.5 \sim 1.0$ & $1.0 \sim 2.0$ & $>2.0$ \\
\hline & & Table 2 Flow velocity patch classification & [Unit: $\mathrm{m} / \mathrm{s}]$ \\
\hline Type & Tranquil velocity & Mediate tranquil velocity & Mediate rapid & Rapid \\
\hline Flow velocity & $0 \sim 0.2$ & $0.2 \sim 1$ & $1 \sim 2$ & $>2.0$ \\
\hline
\end{tabular}

Shannon diversity index $(\mathrm{H})$ has been demonstrated and recommended an effective method in identifying landscape heterogeneity, and is especially sensitive to the unbalanced distribution of patches ${ }^{[16]}$. Thus, Shannon diversity index (equation 1) was used to calculate the water depth $\left(\mathrm{H}_{\mathrm{h}}\right)$ and flow velocity $\left(\mathrm{H}_{\mathrm{v}}\right)$ heterogeneity. In order to reflect the joint effect of water depth and flow velocity heterogeneity, we defined $\mathrm{H}_{\mathrm{d}}$ as depth-velocity diversity index which obtained by multiply $\mathrm{H}_{\mathrm{h}}$ and $\mathrm{H}_{\mathrm{v}}$.

$$
H=-\sum_{i=1}^{m}\left(P_{i}\right) \times \log _{2}\left(P_{i}\right) .
$$


$\mathrm{H}$ refers to the microhabitat heterogeneity, $\mathrm{m}$ is the number of patch types and $\mathrm{P}_{\mathrm{i}}$ represents the proportion of each type of hydraulic environmental patch to the total area of habitat. $\mathrm{H}=0$ means the whole landscape consisted of only one patch.

\section{Results and Discussion}

Depth patch. The proportion of riffle patch declined with the augment of discharge while that of pool patch increased. The proportion of mediate riffle patch increased initially and decreased when the discharge was larger than $52 \mathrm{~m}^{3} / \mathrm{s}$. As for the mediate pool patches, the proportion of it increased firstly and then decreased. When the discharge was $417 \mathrm{~m}^{3} / \mathrm{s}$, the peak value was arrived. Positive relationship was revealed between the area and proportion of pool patch and discharge (Fig.2a).

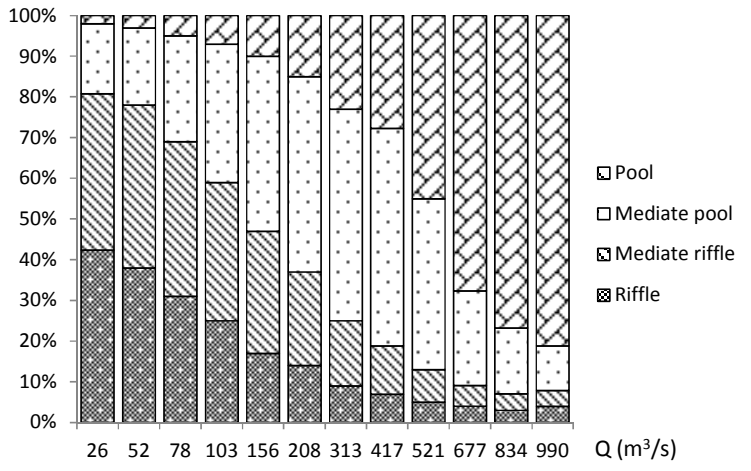

(a) water depth

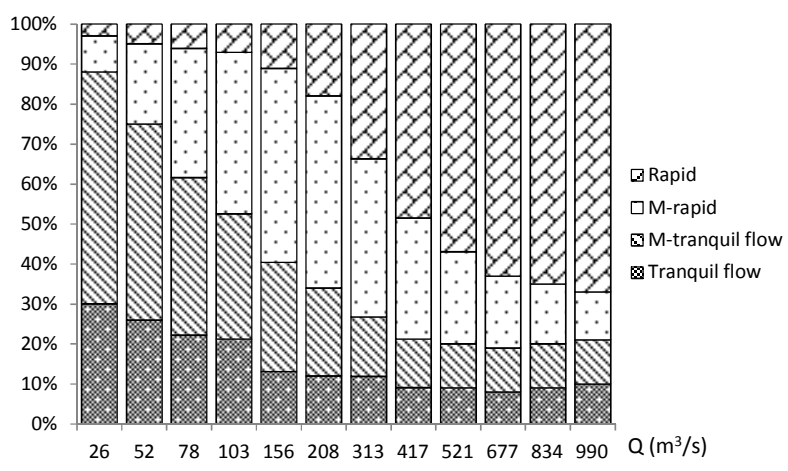

(b) flow velocity

Fig. 2 The proportion of flow velocity and water depth patches
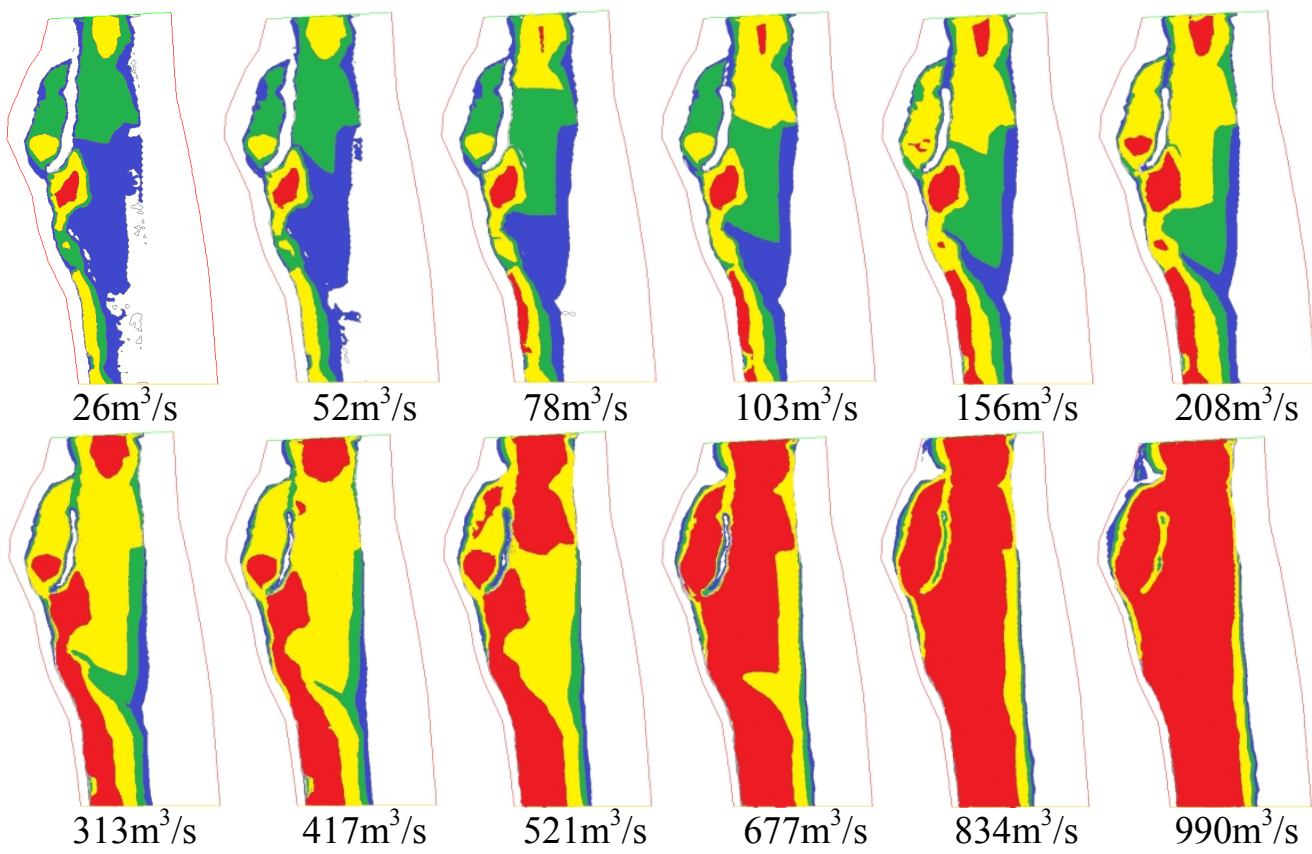

Fig.3 Distribution of depth patch in different discharges

$\square$ Riffle $(0<\mathrm{h} \leq 0.5) ; \square$ Mediate Riffle $(0.5<\mathrm{h} \leq 1.0) ; \square$ Mediate pool $(1.0<\mathrm{h} \leq 2.0) ; \square$ Pool $(\mathrm{h}>2.0)$

Velocity patch. From the results (Fig.2b), we found the variance trend of tranquil flow patch and mediate tranquil patch was similar. Both of them declined with the increasing discharge. The proportion of mediate rapid patch firstly increased and then decreased. The maximum proportion of it was reached when the discharge was $156 \mathrm{~m}^{3} / \mathrm{s}$ and $103 \mathrm{~m}^{3} / \mathrm{s}$. The proportion of rapid patch was positively related with the discharge. 

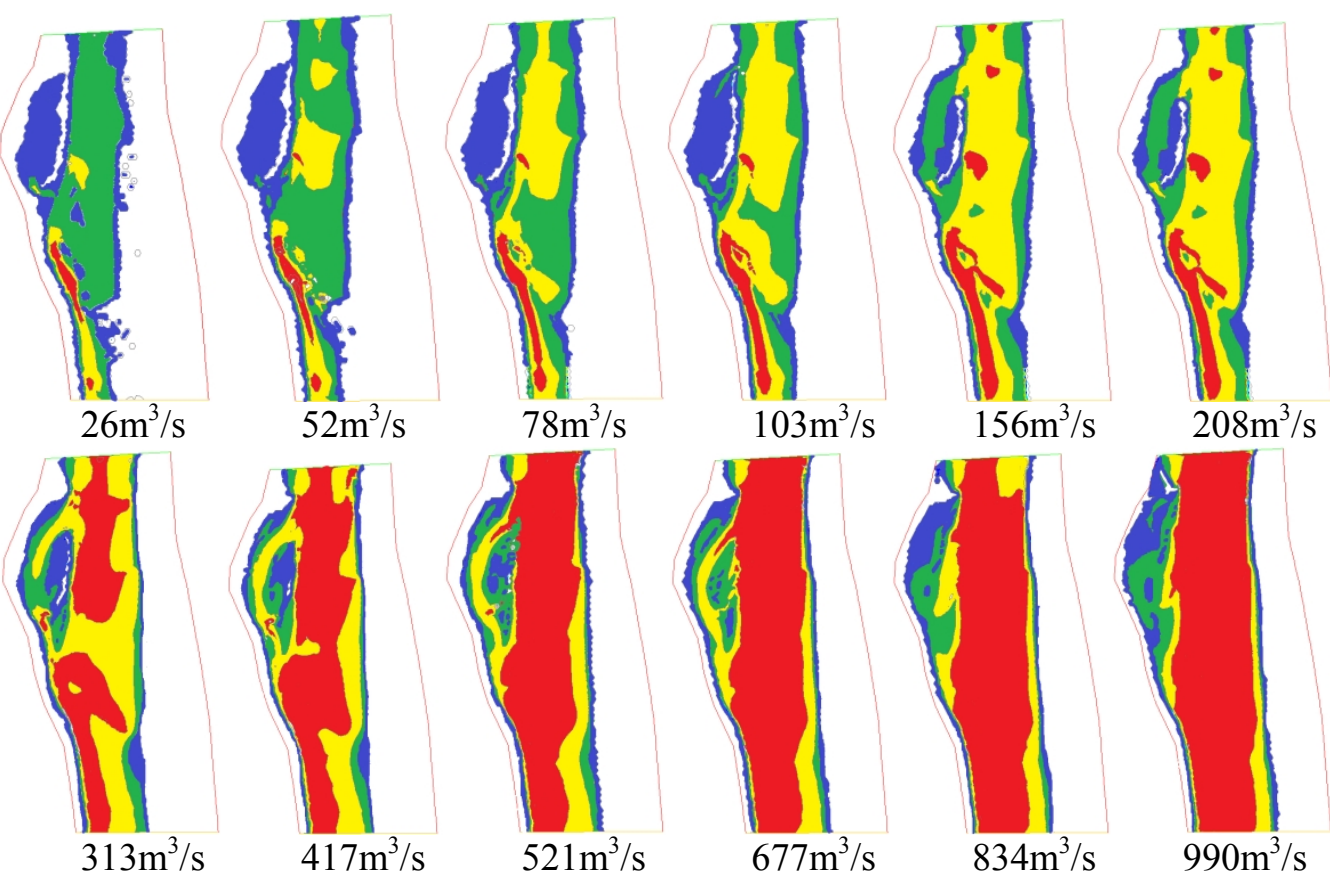

Fig.4 Distribution of velocity patch in different discharges

Tranquil-flow $(0<\mathrm{v} \leq 0.2) ; \square$ Mediate tranquil-flow $(0.2<\mathrm{v} \leq 1.0) ; \square$ Mediate rapid $(1.0<\mathrm{v} \leq 2.0)$; $\square$ Rapid (v>2.0)

Velocity-Depth diversity index of habitat. The maximum $\mathrm{H}_{\mathrm{d}}$ was acquired when the discharge was $156 \mathrm{~m}^{3} / \mathrm{s}$ (Fig.5). From the distribution of water depth patch (Fig. 3), the central part of the river bed is convex and the two terminal sides are straight. There is a river island near the right bank of the river. With the increase of discharge, the island is submerged gradually and finally disappeared. The flow velocity distribution could be inferred from Fig. 4. Generally, the flow water velocity of the right bank is smaller than that of the other parts. This is because the river island blocks the circulation of water. Once the discharge increased, the flow velocity of the central part is enhanced evidently.

When the discharge is $156 \mathrm{~m}^{3} / \mathrm{s}$, mediate pool patch is the domimant patch (43\%). And its value ranges from $1 \mathrm{~m}$ to $2 \mathrm{~m}$. As for the flow velocity, mediate rapid patch accounts for the biggest part $(48 \%)$. The scale of flow velocity and water depth determined by the Velocity-Depth diversity index is similar with the habitat suitable index of spawning of Ya-fish ${ }^{[13,14]}$. In addition, both of the water depth and flow velocity patches distribute relatively even. Therefore, we recommended discharge obtained when the discharge is $156 \mathrm{~m}^{3} / \mathrm{s}$ as optimal ecological flow.

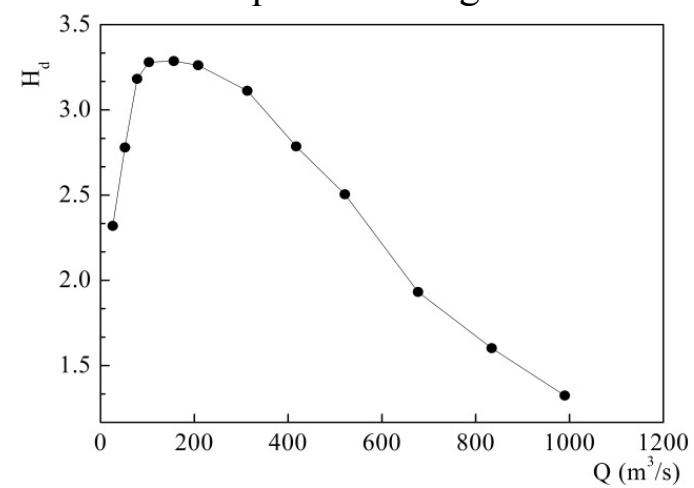

Fig. 5 The curve of depth-velocity diversity index of Lijiahe spawning ground

\section{Conclusion}

Spatial heterogeneity has been widely used in landscape ecology but seldom mentioned in the studies of river habitat of fish. In this study, based on the knowledge of landscape heterogeneity and hydraulics, we put forward depth-velocity diversity index in studying the hydraulic environment of 
fish in the freshwater after being regulated. Finally, we determined that the optimal discharge for fish spawning is $156 \mathrm{~m}^{3} / \mathrm{s}$.

But, in this study, we only investigated the alteration of water depth and flow velocity given that they are two significant factors deciding the successful ration of spawning but also evidently changed once discharge fluctuate in the de-water channel. However, by no means could we ignore other factors of environmental hydraulic, such as temperature and riverbed substrate. And more studies are being looking forward.

\section{References}

[1] Tennant D. L., Instream flow regimens for fish, wildlife, recreation and related environmental resources, J. Fisheries, 1 (1976) 6-10.

[2] Caissie D., El-Jabi N., and Bourgeois G., Instream flow evaluation by hydrologically-based and habitat preference (hydrobiological) techniques, J. Journal of Water science, 11(1998) 347-363.

[3] Bovee K. D., A guide to stream habitat analyses using the instream flow incremental methodology, Instream flow information, E-publishing. Washington, U S Fish and Wildlife Service, 1982 67-73.

[4] Yang Y, Yan Z, Qiao Y., Description and review of hydraulic conditions of fish habitats, J. Journal of Hohai University (Natural Sciences), 2(2007). (In Chinese)

[5] Chen mingqian, Tuo youcai, Wang qingguo., Preliminary study on index system describing hydraulic characteristics of fish spawning ground, J. Chinese Journal of Hydraulic Engineering, (2013) 1303-1308. (In Chinese)

[6] Harman W N, Berg C O., Fresh-Water Mollusca of the Finger Lakes Region of New York. 1970.

[7] Miller S W, Budy P, Schmidt J C., Quantifying Macroinvertebrate Responses to In-Stream Habitat Restoration: Applications of Meta-Analysis to River Restoration, J. Restoration Ecology, 2010, 18(1) 8-19.

[8] Sempeski P, Gaudin P., Habitat selection by grayling — spawning habitats, J. Journal of Fish Biology, 47(1995) 256-265.

[9] Moir H J, Soulsby C, Youngson A., Hydraulic and sedimentary characteristics of habitat utilized by Atlantic salmon for spawning in the Girnock Burn, Scotland. Fisheries Management and Ecology, $5(1998) 241-254$.

[10] Palmer MA, Menninger HL, Bernhardt E., River restoration, habitat heterogeneity and biodiversity: a failure of theory or practice? J. Freshwater Biology 55 (2010) 205-222.

[11] Chen yifeng, Cao wenxuan., Schizothoracinae. Beijing: Science Press, 2000: 273-390.

[12] Li Jia, Wang yurong, et al., Eco-hydraulics method of calculating the lowest ecological water demand in river channels, J. Chinese Journal of Hydraulic Engineering, 2006 (10) 1169-1174. (In Chinese)

[13] Liu Mingyang, Li yong et al., Application of Ecological Spur Dike Repairing Schizothorax Prenanti Spawning Ground, J. Journal of Sichuan University, 5 (2014) 41-46. (In Chinese)

[14] Jowett I G, Richardson J., Habitat preferences of common, riverine New Zealand native fishes and implications for flow management, J. New Zealand Journal of Marine and Freshwater Research, 29(1995) 13-23. 